\title{
Spirituality and healthcare: Towards holistic people- centred healthcare in South Africa
}

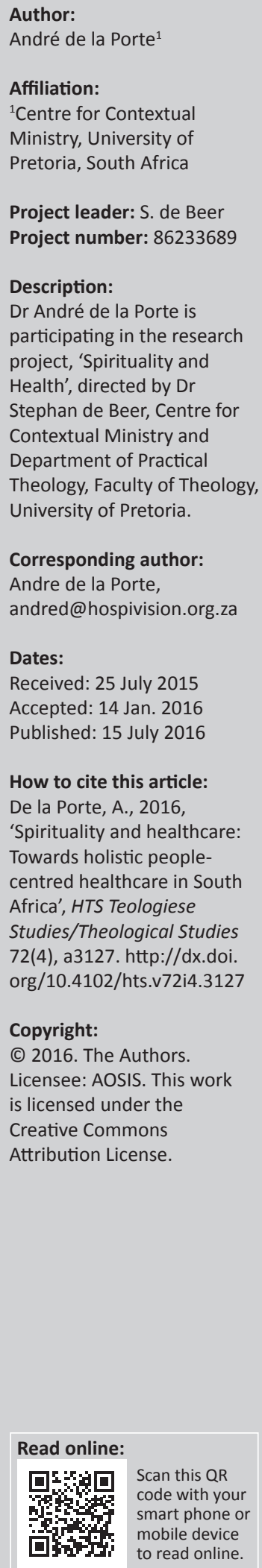

Healthcare in South Africa is in a crisis. Problems with infrastructure, management, human resources and the supply of essential medicines are at a critical level. This is compounded by a high burden of disease and disparity in levels of service delivery, particularly between public and private healthcare. The government has put ambitious plans in place, which are part of the National Development Plan to ward 2030. In the midst of this we find the individual person and their family and community staggering under the suffering caused by disease, poverty, crime and violence. There is a more than $70 \%$ chance that this person and their family and community are trying to make sense of this within a spiritual framework and that they belong to a faith-based community. This article explores the valuable contribution of spirituality, spiritual and pastoral work, the faith-based community (FBC) and faith-based organisations (FBOs) to holistic people-centred healthcare in South Africa.

\section{Introduction}

Healthcare in South Africa is in a crisis. In the 2011 report Reforming healthcare in South Africa: What role for the private sector?, the Centre for Development and Enterprise (CDE) states:

\begin{abstract}
A full-blown crisis of health outcomes developed in South Africa during the 1990s and the first decade of this century. This only received proper political recognition from about 2007, when increasingly frequent media exposure of the public health system's failings created an atmosphere of crisis and scandal. This, along with the brave efforts of health professionals and health NGOs, helped silence high-level denialism about HIV and AIDS in particular and the poor condition of public healthcare in general. Since 2007 the government has been much franker in acknowledging shortcomings in both policy and delivery and has promised to tackle them with determination. (p. 3)
\end{abstract}

This situation should be of grave concern to faith-based organisations (FBOs) who render services in the healthcare environment as well as faith-based communities (FBCs) whose members utilise healthcare services. Practical theologians are challenged by this situation to reflect on the meaning of health and wellness and how it can contribute towards restoration and healing. It is simultaneously a warning and a clarion call to action. Heitink (1999:6) defines practical theology as '... the empirically oriented theological theory of the mediation of the Christian faith in the praxis of modern society'. Practical theology is a theological theory of action that includes hermeneutical, strategic and empirical reflection. For Louw (1998) practical theology has to do with the praxis of God that is mediated through meaningful human action within a specific context. Based on Gadamer's hermeneutical circle, Osmer (2008:20-25) emphasises the interpretive function of practical theology.

These authors also stress the importance of contextuality. All human action is embedded in cultural contexts in which attitudes, values, customs, and rituals play an important role. Contextuality further refers to the ethos, undergirding philosophy of life, structural components, religious convictions and belief systems. Contextuality is closely linked to relationality. Hence, the importance to assess human behaviour and thinking within a systemic network of relationships (Louw 1998:75-79).

When confronted with such a multiplicity of factors, Osmer's (2008:4) four tasks of contemporary practical theology can provide a practical framework to engage with contextuality. These four tasks are:

- Descriptive-empirical: What is going on? Gathering information to better understand particular episodes, situations, or contexts.

- Interpretive: Why is this going on? Entering into a dialogue with the social sciences to interpret and explain why certain actions and patterns are taking place. 
- Normative: What ought to be going on? Raising normative questions from the perspectives of theology, ethics and other fields.

- Pragmatic: How might we respond? Forming an action plan and undertaking specific responses that seek to shape the episode, situation, or context in desirable directions.

Keeping in mind that these tasks should not be seen as linear phases, they will serve as a guideline to reflect on the following key question: What is the contribution of spirituality, spiritual and pastoral work and the FBCs and FBOs to holistic people-centred healthcare in South Africa? The first tasks are to understand the 'what' and 'why' of the situation with regard to spirituality and healthcare. In the second part of the article normative and pragmatic questions will be addressed.

\section{The South African healthcare situation}

According to the World Health Organisation (2010:1-5) a wellfunctioning health system responds in a balanced way to a population's needs and expectations by improving the health status of individuals, families and communities. The function of the health system is also to defend the population against what threatens its health, to protect people against the financial consequences of ill-health, to provide equitable access to people-centred care and to make it possible for people to participate in decisions affecting their health and health system. For a healthcare system to render quality health services to all people, when and where they need them, it requires a robust financing mechanism, a well-trained and adequately paid workforce, reliable information on which to base decisions and policies, well-maintained facilities and logistics to deliver quality medicines to individuals and populations. Healthcare includes preventative, curative and palliative services.

The public health sector is institutionally fragmented and characterised by a poor standard of infrastructure, skills shortages, poor staff attitudes, low levels of patient satisfaction, incompetent management, continuing human resources and financial crises, and with starkly different health outcomes for different socio-economic groups. The Department of Health's Strategic Plan for 2010-2013 and 10 Point Plan for 2009-2014 has been developed to address these challenges. In its August 2011 Green Paper on National Health Insurance, the government set the ambitious goal of achieving universal access to quality healthcare over the next fourteen years. Unfortunately, there are also significant levels of misunderstanding and mistrust between various role players, often as a result of ideological differences and resentment over the disparity in resource levels.

The above-mentioned CDE report (2011) further highlights the complexities of the South African health sector:

The coexistence between a failing public health sector and a private sector that serves a significant minority with high quality healthcare is the most contentious aspect of the health reform debate in South Africa. There is a widespread tendency in this debate to dismiss the contribution of the private sector to overall health outcomes, to be suspicious of the motives of private health sector players and to challenge the very legitimacy of private health provision. (p. 15)

It should be emphasised that there are also many dedicated people working under exceptionally difficult conditions in public health services. Some notable successes have also been achieved. This should be recognised, along with the failings of the public system. The CDE report (2011:50) also highlights the successful elements of existing public-private partnerships. Private service-providers deliver care of consistently high quality to far more people than is usually acknowledged. The fact that it is private, and that some parts of it operate for profit, does not detract from this. The country should play to its strengths and turn a deteriorating situation through a collaborative national approach. The National Planning Commission (2013:12-22) has identified healthcare as one of 10 key strategic areas in the National Development Plan.

\section{Spirituality and healthcare: An overview}

A World Health Organisation report published in 1998 recognised that:

... until recently the health professions have largely followed a medical model, which seeks to treat patients by focusing on medicines and surgery, and gives less importance to beliefs and to faith - in healing, in the physician and in the doctor-patient relationship. This reductionism or mechanistic view of patients as being only a material body is no longer satisfactory. Patients and physicians have begun to realise the value of elements such as faith, hope and compassion in the healing process. The value of such 'spiritual' elements in health and quality of life has led to research in this field in an attempt to move towards a more holistic view of health that includes a non-material dimension (emphasising the seamless connections between mind and body). (p. 2)

In the same year the Duke University's Center for Spirituality, Theology and Health (CSTH) was founded. In the document Vision, mission, accomplishments and future plans (1998), the mission of the CSTH is summed up as follows:

(1) Conduct research on the relationships between religion, spirituality, and health, (2) train others to do so, (3) interpret the research for clinical and societal applications, (4) explore the meaning of the research findings within the context of theological positions, and (5) discuss how those theological positions might inform the design of future research. (p. 1)

As part of the work of the Centre, Koenig, McCullough and Larson published the Handbook of religion and health in 2001. Their research covers the whole of medicine and is based on 1200 research studies and 400 reviews. The second edition of the handbook was published in 2012 and now includes a review of more than 3000 studies (Koenig, King \& Carson 2012). The handbook covers an overview on the effect of religion on health. It has a section on the relationship between religion and mental health covering subjects such as well- 
being, depression, suicide, anxiety disorders as well as alcohol and drug abuse. The discussion on the relationship between religion and physical health addresses heart disease, hypertension, Alzheimer's disease and dementia, immune functions, cancer and mortality. Health behaviours and disease prevention are also positively influenced by religion. In conclusion Koenig et al. (2012) state:

What have all these studies found? While some report that Religion/Spirituality (R/S) people experience worse mental health $(4 \%)$ and poorer physical health $(8.5 \%)$, many more studies (over eighteen hundred) find significant positive relationships between R/S involvement and mental or physical health. Indeed, at least two-thirds of these studies report that R/S people experience more positive emotions (well-being, happiness, life satisfaction), fewer emotional disorders (depression, anxiety, suicide, substance abuse), more social connections (social support, marital stability, social capital) and live healthier lifestyles (more exercise, better diet, less risky sexual activity, less cigarette smoking, more diseases screening, better compliance with treatment). (pp. 600-601)

The George Washington Institute for Spirituality and Health (GWish) was established in May 2001 as a leading organisation on education and clinical issues related to spirituality and health. The mission of GWish is to work toward 'a more compassionate system of healthcare by restoring the heart and humanity of medicine through research, education and policy work focused on bringing increased attention to the spiritual needs of patients, families and healthcare professionals' (GWish, n.d.). In 2012 the director of GWish (Puchalski) was one of the editors of the Oxford textbook on spirituality in healthcare (Cobb, Puchalski \& Rumbold 2012). The textbook is wide ranging and addresses issues such as personhood, belief, hope, meaning making, compassion, dignity, suffering and the role of culture. In the practice section aspects relating to models of spiritual care, nursing, psychiatry, social work, care of children and palliative care are discussed. The textbook also offers sections on research, policy and education. Pellegrino (in Cobb et al. 2012) observes:

Experienced clinicians have long known that true healing extends beyond the artful use of medical knowledge. They grasped intuitively that serious or fatal illness was an ontological assault, an existential assault on the whole of the patient's lived world. To heal, the physician must recognise the starkness of the patient's encounter with his own finitude, i.e. with his mortality and inherent limitations. Healing of the psychosocial-biological is of itself insufficient to repair existential disarray of the patient's life without recognizing the spiritual origins of the disarray. (p. 22)

The Forschungsinstitut für Spiritualität und Gesundheit (FISH; Research institute for Spirituality and Health) was established in 2005 at the University Hospital in Bern, Switzerland and functions as a research network for Europe. Since 2008 the FISH has also organised the bi-annual conference on this theme. During the second European Conference on Religion, Spirituality and Health (Bern, May 2010) the representatives of different European and international organisations and initiatives gathered for a special meeting and founded the International Society on Spirituality, Religion and Health (ISSRH), dedicated to research, education and practice. The first Australian conference on spirituality and health was held in 2005 in Adelaide (and thereafter presented bi-annually). The conferences address themes such as forgiveness, compassion, aging and palliative care.

The last ten years have witnessed a dramatic increase in studies of spirituality in healthcare. This research has demonstrated robust links between spirituality and health. What is emphasised throughout is the importance of integrating spirituality into the practice of healthcare. A multidisciplinary approach is needed with the person at the centre, making room for the distinctive perspectives and practices of social scientists, health professionals, chaplains, and clergy. The availability of spiritual and pastoral workers trained to work in healthcare is emphasised throughout the research.

In reviewing the role of spirituality in psychiatry, Culliford (2002:259) indicates a shift in paradigms. Traditional models tend to be reductionist with an emphasis on positivist, empiricist, dualistic and mechanistic approaches. More recent models are constructivist and holistic and take a participant-observer stance. There is a move away from a simple and linear cause and effect interpretation of human action. Postmodern approaches see the world as emergent and consisting of multiple and overlapping realities. In traditional approaches the world is seen as value free and independent from the observer. In the new approach the world is seen as value-laden with intrinsic meaning which is reflected in various interpretations. Inner and outer realities are experienced as interconnected and indivisible.

\section{Spiritual and pastoral work in healthcare}

\section{The need for spiritual and pastoral work in healthcare}

The International Society for Quality in Healthcare (www. isqua.org) is a global organisation for healthcare accreditation of national and regional healthcare facilities. It was founded in 1985 and currently spans 100 countries on 5 continents. ISQua's mission is to inspire, promote and support continuous improvement in the safety and quality of healthcare worldwide. ISQua's accreditation system covers the entire continuum of care, ranging from systems and processes to quality of patient care and performance. It also includes patients and their loved ones who are a valuable resource as in the process of achieving the goal of excellence in healthcare delivery and outcomes. Part of ISQua's accreditation system is based on the WHO Patient safety assessment manual (2011). Standard B.7.2.3 states: 'The hospital has a place for prayers and meets patients' spiritual and religious needs' (2011:46).

The ISQua system is based on the Planetree model (www. planetree.org). Planetree was founded in 1978 and currently its membership comprises over 500 institutions and organisations in five countries. Planetree's philosophy is 
based on a simple premise: care should be organised first and foremost around the needs of patients. The Planetree Patientcentred care improvement guide (2008) is structured around the following important components of the healthcare experience: communication, personalisation of care, continuity of care, access to information, family involvement, the environment of care, spirituality, integrative medicine, caring for the community and care for the caregiver. The assessment criteria for spirituality include the following (2008:14):

- Resources are available to staff to educate them on different religious beliefs / traditions related to health and healing.

- Spiritual assessments look beyond a patient's faith traditions to also capture what comforts and centres them.

- Space is available for both quiet contemplation and communal worship.

The Council for Health Service Accreditation in South Africa (www.cohsasa.org) was established in 1996 to assist healthcare facilities in developing countries to deliver quality healthcare to their clients through sustained improvement, using internationally recognised standards and based on patient safety principles and operational research. COHSASA is accredited by ISQua. The COHSASA Hospital Standards (Version 6.6, June 2010 through to July 2014) currently does not have a standard for spirituality. However, the COHSASA Hospice Palliative Care Standards (1st edn., August 2010 through to July 2014) does include a standard for spiritual care which states:

7.3.1: The spiritual needs of patients and families are identified and addressed according to their religious and cultural beliefs and values.

\section{Intent of 7.3.1}

The spiritual care service is managed by a suitably trained and/ or experienced co-ordinator in line with the policies and procedures that guide the service. It provides spiritual counselling and bereavement support to patients and families in line with organisational policies and procedures, which take gender into account. An assessment of spiritual concerns includes, but is not limited to meaning, purpose, beliefs, guilt, forgiveness and unfinished life tasks. Care reflects respect for different religious and cultural beliefs and rituals.

\section{Criteria for 7.3.1}

- A chaplain or spiritual care coordinator who is suitably qualified and experienced coordinates the spiritual care of patients and families.

- Suitably trained spiritual counsellors is available to meet the spiritual needs of patients and/or families when required.

- Spiritual support team members have access to information about different religions and cultural practices related to illness, death and bereavement.

- The spiritual support team facilitates the religious or spiritual rituals important to the patient and family, especially at the time of death.

- Suitably trained spiritual counsellors contributes to the bereavement support of the family and members of the care team are identified.
- Spiritual support is documented in the patient's record. (p. 33)

In North America spiritual and pastoral workers who function in the healthcare environment are accredited by the Joint Commission for Accreditation of Pastoral Service (www.nacc.org) which has more than 10000 members. The European Network of Healthcare Chaplaincy (http://www. enhcc.eu/) consists of representatives from churches, faiths and national associations. Its purpose is to enable its participants, who serve in the area of the multi-disciplinary field of healthcare, to work for the development of professional guidelines required to minister to the existential and spiritual needs of patients, relatives and staff, drawing on personal, religious, cultural and community resources and to promote a high quality standard of healthcare chaplaincy in Europe.

In South Africa there is no statutory requirement or official system in place for accreditation and certification of spiritual and pastoral workers in healthcare. Neetling (2003) has done a study regarding the relevance of pastoral work in South Africa with specific reference to the Southern African Association for Pastoral Work (SAAP; http://www.saap.za. net/). Neetling (2003:82) concludes that pastoral counselling is a possible national health resource for healthcare, cost effectiveness, spirituality, social change, reconciliation and multi-cultural application.

\section{Clinical pastoral and/or spiritual education}

Internationally the training for accredited and/or certified spiritual and pastoral care workers is based on the principles and practices of Clinical Pastoral Education (CPE). Anton T. Boisen (1876-1965) coined the phrase the living human document'. He is widely regarded as the founder of the CPE movement in the USA. The Association for Clinical Pastoral Education (ACPE; http://www.acpe.edu/) defines CPE as an interfaith professional education for ministry. It brings theological students and ministers of all faiths (pastors, priests, rabbis, imams and others) into supervised encounter with persons in crisis. Out of an intense involvement with persons in need, and the feedback from peers and teachers, students develop new awareness of themselves as persons and of the needs of those to whom they minister. From theological reflection on specific human situations they gain a new understanding of ministry and develop their pastoral identity, interpersonal professional competence, and spirituality, including the skills of pastoral care and counselling, pastoral assessment, integration of theology and ministry, group leadership and pastoral theological reflection. Within the interdisciplinary team process of helping persons, they develop skills in interpersonal and inter-professional relationships.

Ward (2001) has done an extensive review and evaluation of CPE in the South African context. She emphasises that CPE provides a valuable experiential training and personal growth opportunity for spiritual and pastoral counsellors in 
a clinical context. "The pressing problems facing ministry today demand that training for ministry must incorporate practical experience alongside theoretical knowledge' (2001:227). The 'action and/or reflection' model (with the verbatim, personal and group supervision at its core) and exposure to the clinical setting provides a challenging learning environment (2001:231-235). She warns, however, that CPE might not fit easily into the culture and methods of ministry training in South Africa (2001:242). For CPE to be valid it must incorporate the cross-cultural customs and traditions in its context. Other challenges that need to be addressed are language, gender issues and questions of length and context.

It is clear that spiritual and pastoral work should be an essential (if not mandatory) part of holistic people-centred healthcare. It also provides a valuable opportunity for personal growth and ministerial training and practice.

South Africa with its 342 Public (National Department of Health; http://www.doh.gov.za) and 216 private (Hospital Association of South Africa; http:/ / www.hasa.co.za) hospitals offers a huge challenge and opportunity. On the whole, hospital managements are positive towards the provision of spiritual and pastoral care and services. South Africa does, however, not have systems in place as in North-America, Europe and Australia where spiritual/pastoral/chaplaincy services are funded by government or by hospitals themselves. Bross and DeAngelo (2012) emphasise that strategic planning should be key to the functioning of spiritual/pastoral/ chaplaincy departments and services and should include funding and infrastructure development. This will be crucial in the South African context and cannot be accomplished without the support and involvement of the FBCs and FBOs.

\section{The faith-based community and faith-based organisations in healthcare}

South Africa has a very substantial burden of disease, not only from HIV and AIDS but also from preventable conditions arising from poor sanitation, nutrition and other conditions of poverty, as well as a growing burden of non-communicable disease affected by lifestyle. High levels of crime, physical trauma and violence places a further burden on the healthcare system. The important role of FBCs and FBOs is already indicated in the Department of Social Development's 2011 report on the South African non-profit sector. Faith-based organisations are the third biggest sector $(12 \%=8839$ out of a total of 76175), after Social Services (34\%) and Development and Housing $(21 \%)$. This is followed by the Health Sector $(11 \%=8723)$. The South African government's National Strategic Plan on HIV, STIs and TB 2012-2016 (n.d.) recognises the important role of the faith-based sector and the networks it provides. In the 2012 journal article titled, 'The scale of faith based organization participation in health service delivery in developing countries', Kagawa, Anglemyer and Montagu (2012) estimated that faith-based organisations play a substantial role in providing healthcare in developing countries and in some cases provide up to $70 \%$ of all healthcare services.
A hallmark of South African society, apart from its diversity and inequalities, is the religious involvement of people and communities. In the 2011 census, questions about religion were not included. The 2001 census indicated that more than $80 \%$ of South Africans had some religious affiliation (http:/ / www.statssa.gov.za/). However, the 2012 Gallup poll indicated a $19 \%$ decline in religiosity from $83 \%$ (2005) to $64 \%$ (2012). A very interesting trend is that levels of religiosity are much higher in low-income groups $(66 \%)$ than in high income groups (49\%).

Magezi (2008) is therefore correct in emphasising the churches' contribution to national health and well-being. The church is a subsystem of the community and as such can influence the community and society (Magezi 2008:273). As much as the church, a clinic or a hospital must also be considered as part of the community, and the church (FBCs and FBOs) can make an important contribution to the function and impact of these facilities. The church also has access to and can offer physical and human resources to the community, part of which can be health related (Magezi 2008:274). The church provides social and community cohesion and its leaders can play an important role in societal and moral transformation (Magezi 2008:274). Magezi (2012:167) pleads for the repositioning of churches from the periphery to the centre in order to make a meaningful contribution to public healthcare. He indicates three areas of participation: increasing access to primary and preventive care, improving delivery and quality of healthcare and improving patients' self-management of their disease. FBOs and FBCs can also play an important role in community healthcare and primary healthcare. De Gruchy (2007) indicates the value that religion can add to health in the following areas: Religion offers presence; Religion offers an integration of tangible and intangible health promoting factors; Religion offers relationships and networks; Religion offers an interpretive framework.

What needs to be added is that the faith-based community also provides context for care, compassion and hope. People throughout history have dealt with illness, loss, suffering, trauma and pain in spiritual ways. According to Louw (2008:118-122), illness must be seen as a conflict and existential crisis. It causes conflict with the body, the self (identity crisis), the environment, and a crisis of faith and ultimately an existential life crisis in which our sense of purposefulness and direction is questioned. Illness further threatens our will to live, confronts us with our finites and mortality as well as with our past actions and its consequences for the future. Representatives of that community (whether professional or volunteer) build a bridge to the faith community to communicate that we are part of a bigger group who share in our humanity and vulnerability. The faith-based community is also an important resource to support healthcare workers in their commitment to provide compassionate care.

It is clear that spirituality, spiritual and pastoral work and FBCs and/or FBOs have an essential role to play in the provision of holistic people-centred healthcare. This is 
internationally recognised and there are already excellent best practice models available. However, the nature and extent of this contribution in the South African context and how it can be enhanced is not easy to define and should be the subject of further practical theological research.

\section{A dynamic understanding of health and illness}

In our modern society with its focus on life, health, production, achievement and success those that are ill are often subject to the stigma of uselessness and futility (Louw 2008:10). It is therefore important to take note of the WHO definition of health that was accepted in 1948: 'Health is a state of complete physical, mental and social well-being and not merely the absence of disease or infirmity'. It is important that the starting point for the definition is health and not illness and a holistic view of health is embraced. However, this definition is in itself also problematic as it makes attainment of 'health' virtually impossible.

The benefits to humanity of the advance in medical sciences cannot be denied. The danger is obvious that a bio-medical model with its focus on treatment and cure gains supremacy over all other models and interpretations. Swinton (2012: 110-113) points out the importance of understanding knowledge systems in healthcare. On the one hand there is nomothetic knowledge, which is gained through the application of the scientific method in, for example, experiments and randomised control trails. The supremacy of this kind of knowledge is often taken for granted and gives rise to empiricism. On the other hand, we have ideographic knowledge, which assumes that knowledge can be discovered through unique, non-replicable experiences. Nomothetic knowledge takes the 'typical patient' and tested treatment regimens as its starting point. Ideographic knowledge perceives the uniqueness of people and the particularity of meaning and experience. The bio-medical approach can only find its rightful place in healthcare that is holistic and people-centred. Louw (2008:47) is therefore correct in stating that health includes responsible medical practices as well as the utilisation of spiritual, cultural, psychological and social sources. This is partly why a practical theological approach must be part of the discussion on holistic people-centred healthcare.

The theme of an 'African' interpretation of illness, health and spirituality is of particular relevance for the South African context. Louw (2008:147) makes the observation that it is not possible to refer to the term 'African' as a homogenous allencompassing concept. He refers to Mazrui's contention that there is no tradition of an African identity and that Europeans gave their identity as 'Africans'. Africa should therefore rather be seen as a philosophical concept that describes the diversity and complexity of cultural and contextual settings. For Louw (2008) 'Africa' is also a spiritual category:

It is an inclusive category describing the 'spirit' of people living in Africa. Africa functions as a hermeneutical paradigm indicating a unique approach to life that differs from the analytical approach emanating from Western thinking and
Hellenism. Africa is an attempt to describe and interpret how different cultures contribute to a better understanding of the dominant features of a mode of living and a philosophy of life; it refers to, among other things, the needs and unique struggles of people in this continent. (p. 47)

According to Manala (2005:103-117), the African worldview is holistic, characterised by strong community bonds, has dynamism and vitalism, has a heightened sense of the sacred and is anthropocentric. Ubuntu is central to the African way of life. According to Mbigi (1997):

Ubuntu (or unhu in Shona) is a literal translation for collective personhood and collective morality. It is best expressed in Xhosa proverb, umuntu ngumntu ngabanye abantu which simply means I am because we are. We have to encounter the collective we before we encounter the collective I. I am only through others. (p. 2)

Mbigi (1997:110) emphasises that 'the emancipation concept of Ubuntu can only be of significance in the context of collective work and survival issues'. He pleads for the revitalisation of the values Ubuntu, namely, morality, respect, human dignity, humaneness, compassion, care and understanding. Ubuntu requires one to respect others if one is to respect themself. This emphasises the fact that Ubuntu values the good of the community above self-interest. If the community is well, an individual will also be well. When faced with illness, Ubuntu, which puts more emphasis on respect, honesty and trustworthiness, plays an important role in care.

Manala (2005:137) states that in African thought health equals life. To be healthy means to have an unhindered flow of life in all aspects of one's being. In Africa illness is therefore one of the major enemies of human life. It is an indication that the existence of life is threatened. It is a decrease in life, reduced participation, and impaired wholeness. It therefore stifles the dynamic and creative life of the community. It is indeed a step in the direction of death (Manala 2005:140). In the African worldview, illness is not linked to bacteria, viruses and infection, but to a disruption of the system, the societal order and the web of life. The question who caused the illness is important in the African interpretation. Suspicion of underlying factors and the influence of evil powers are therefore present. Illness is also a cosmic event that befalls a person and cannot be separated from the reality of death. The degree of illness is determined by the concept of order, balance and harmony. A person can therefore only be healthy if the relationships have been restored (Louw 2008:169; Manala 2005:140-143).

This relational quality is crucial for an intercultural approach to pastoral care and counselling. Lartey (2012:140) also proposes a relational understanding of spiritual care that includes the following components: the relationship with transcendence, intra-personal (relationship with self), interpersonal (relationship with another), corporate (relationship among people) and spatial (relationship with both place and things).

Louw (2008:23-24) emphasises a qualitative approach to health and illness that is based on a dynamic understanding 
of the health-illness field as a continuum. Instead of a circular model where healthy people are moved to ill health and back to health, a dynamic developmental model is suggested which moves reflexively and spirally. The interaction between sickness and health is determined by the person's lifestyle, responsive behaviour, quality of maturity and / or spirituality, ability to grow, learn and adapt as well as the available support systems. Health therefore has a religious-ethical component, which takes as a starting point a person's source of faith that enables them to live meaningfully (Louw 2008:47). The same can obviously be said of illness. We should (as pointed out above) be careful not to see illness just as the antithesis of health.

\section{Spirituality in health and illness}

This leads us to the following important question: What then is holistic people-centred care? Puchalski and Ferrell (2010) have captured its essence:

People deserve 'total care' where they can speak authentically about their illness and where their spiritual needs as well as their physical, social and emotional needs are addressed. Illness, aging, and the prospect of dying can trigger profound questions about who people are, what their life meant, and what will become of them during the course of their illness and perhaps when they die. Who am I? How will I be remembered? These questions have the same importance in patients' life as do questions about treatment. (p. 3)

Louw (2008:9) states that coping with illness is an art when the patient sees their illness as a very special opportunity for growth. Illness can also be a special vocation and responsibility in the context of our living relationship with God and loving relationship with others. Coping with illness has to do with finding meaning in suffering, trusting when everything seems futile, transcending the anxiety of those around us and living with hope in the face of death. Louw (2008:10) emphasises that the task of pastoral care is not only to sustain the sick, but also to prepare the healthy for the crisis and opportunity of illness.

\section{For Louw (2008) 'cura vitae' (the healing of life) is about:}

... a theology of life and the healing of life from the viewpoint of Christian spirituality. It is about how new life in the risen Christ and the indwelling presence of the Spirit can contribute to the empowerment of human beings. It is about hope, care and the endeavour to give meaning to life within the reality of suffering, our human vulnerability, and the ever-present predicament of trauma, illness and sickness. (p. 11)

Spirituality is certainly a buzz word in contemporary society. It is however open to a wide variety of interpretations that stretches from the clinical medical interpretations to esoteric fields such as paranormal psychology. In "The "turn" to spirituality' Kourie (2006) has managed to capture both the essence and diversity of the concept:

Spirituality refers to the raison-d'être of one's existence, the meaning and values to which one ascribes. Thus everyone embodies a spirituality, be it nihilistic, materialistic, humanistic, or religious. There are diverse spiritualities, each one culturespecific, expressing its own historical, sociological, theological, linguistic and philosophical orientation. Post-patriarchal and telluric, contemporary spirituality affects all areas of society, including the business world, education, healthcare, the arts, ecology, politics, religion and particularly the academy, where new programmes in spirituality are attracting a large number of students. The new surge of interest in spirituality is a force for personal and societal transformation. (p. 22)

In African spirituality God appears to be both distant (remote) and near, transcendent and immanent. Divinity is perceived in terms of vitalism, as a force that moves and rules humanity and determines their fate in the world. In African thought inclusiveness is important and, therefore, African religion is both communal and anthropocentric. The role and veneration of ancestors in African spirituality emphasise the unity and continuity of life. African spirituality cannot be separated from the complexity of guilt and shame experiences (Louw 2008:160-165).

Traditionally, healthcare practitioners did not want to engage with 'spirituality' because it was more or less equated to 'religion' and thus seen as outside the scope of healthcare. This has changed, as was indicated in this article. The healthcare benefits of religion and spirituality are acknowledged and it has become part of the discussion about health and illness. There is broadening consensus that must be taken into account by healthcare workers in general when diagnosing and developing and accessing treatment plans. Religion and spirituality can also play an important role in the life of a healthcare worker. In many cases it is tied to a sense of calling or a personal philosophy about care. It also plays a role in resilience, coping with a stressful environment and preventing burnout.

\section{Spiritual and pastoral work in healthcare}

The broad consensus about the role of spirituality and religion in healthcare also means that the place, nature and scope of spiritual and pastoral work are re-evaluated. Kerugmatic and confessional approaches to pastoral work are not favoured in the healthcare environment, as these presume the 'proclamation' of a message or the confession of sins based on a very limited biblical worldview. Louw (1998:66-77) has chosen the concept of 'encounter' as central metaphor for spiritual and pastoral care. Pastoral events create an encounter in which a mutual God-human relationship takes place. It implies reciprocity and interaction as well as a partnership and togetherness in which a dialogue can take place. Encounter implies being aware of somebody's presence as well as experiencing oneself. It is an event of knowing oneself and the other on an existential level and is part of a process of understanding and interpretation. It is transformational in nature and nobody leaves an encounter unchanged. Finally, encounter is characterised by dualities of distance and closeness, challenging and listening, dialogue and action. 
'Encounter' is best experienced and understood within a narrative framework (which is also an essential part of African culture). The practice of storytelling, understanding and changing is based on the principles of hermeneutics and the hermeneutical circle of understanding (Capps 1989: 22-38; Gerkin 1997:6-11; Heitink 1999:178-200; Louw 1998:86-100). Hermeneutics enables us to understand the conditions for, principles of, and execution of the process of understanding. On the one hand we have to understand 'God's story' and his journey with humanity as it is reflected in Scripture. On the other hand we must understand the 'human story' and the individual story of the person we have an encounter with. Hermeneutically speaking we want to understand and interpret the human story in the context of God's story so that a fusion of horizons can take place. Thus, the individual story will not only be communicated, understood and interpreted but also transformed through the pastoral encounter.

A narrative-hermeneutical approach is particularly relevant in multi-cultural contexts. Not only do we have diverse cultures in society playing a role but also the 'culture' of the medical environment and healthcare. This environment has its own language, principles and interpretative systems. Often patients experience that their own interpretive systems break down in this environment.

\section{Conclusion}

Let us revisit the four tasks of practical theology identified by Osmer (2008:4). From a descriptive-empirical perspective it is clear that spirituality, spiritual and pastoral work, the faithbased community and faith-based organisations can make a valuable contribution to holistic people-centred healthcare in South Africa. We are faced with a complex interpretive task because, on the one hand, this must take place within an African context and worldview. On the other hand, the modern healthcare environment will require that we must work within a well-defined framework. Normatively speaking, we need to develop a framework that is theologically grounded, contextually relevant (for the South African healthcare environment), inclusive and pluralistic (making room for Western medicine and African worldviews, culture and practices). On a pragmatic level our approach should be empirically and methodologically sound and consistent, as well as evidence based (taking note of and developing best practice policies and procedures for the South African context). Key to this will be the creative mobilisation, use and management of available and potential physical and human resources.

Having said this, we must constantly be reminded that there are more to the human being and their existence than what can be researched, described and evaluated. 'Spirituality' and 'health' will always have elements that will not comply with nomothetic knowledge systems. Crisis, trauma, illness, loss, suffering and death are part of our human condition and will continue to challenge our conceptual frameworks and quest to find meaning in the midst thereof.

\section{Acknowledgements Competing interests}

The author declares that he has no financial or personal relationships which may have inappropriately influenced him in writing this article.

\section{References}

Bross, W.L. \& DeAngelo, P., 2012, 'Strategic planning: A basis for all infrastructure development and growth within spiritual/pastoral care', in S.B. Roberts (ed.) Professional spiritual and pastoral care, pp. 313-329, Skylight Paths, Woodstock, VT. Capps, D., 1998, Living stories, Fortress Press, Philadelphia, PA.

Centre for Development and Enterprise, 2011, Reforming healthcare in South Africa: What role for the private sector?, viewed 20 January 2014, from http://www. cde.org.za/wp-content/uploads/2012/12/REFORMING\%20HEALTHCARE\%20 IN\%20SA\%2Ofull\%20report.pdf

Cobb, M.R., Puchalski, C.M. \& Rumbold, B. (eds.), 2012, Oxford textbook on spirituality in health care, Oxford University Press, New York.

Culliford, L., 2002, 'Spiritual care and psychiatric treatment: An introduction', Advances in Psychiatric Treatment 8, 249-261.

De Gruchy, S., 2007, 'Taking religion seriously: Some thoughts on "respectful dialogue" between religion and public health in Africa', viewed 20 January 2013, from http://www.arhap.uct.ac.za/downloads/ARHAP_colloquium2007.pdf

Department of Health, n.d., 'The 10 point plan', viewed 14 February 2014, from http://www.hst.org.za/sites/default/files/ks_1V2_10pointplan.pdf

Department of Health, 2010, Strategic plan 2010-2013, viewed 21 January 2014, from http://www.nationalplanningcycles.org/sites/default/files/country docs/ South\%20Africa/south_africa_strategic_health_plan_2010-2013.pdf

Department of Health, 2011, Green paper on national health insurance, viewed 21 January 2014, from http://www.hst.org.za/sites/default/files/2bcce61d2d1b8 d972af41ab0e2c8a4ab.pdf

Duke University Center for Spirituality, Theology and Health, 1998, Vision, mission accomplishments and future plans, viewed 14 December 2012, from http://www. spiritualityandhealth.duke.edu/resources/pdfs/CSTH_Vision_Mission Accomplishments_and_Future.pdf

Forschungsinstitut für Spiritualität und Gesundheit - Research Institute for Spirituality and Health, 2005, viewed 9 January 2012, from http://www.fisg.ch

George Washington Institute for Spirituality and Health, n.d., 'GWish information leaflet', viewed 15 December 2012, from http://www.gwumc.edu/gwish/pdf/ gwish_brochure.pdf

Gerkin, C.V., 1997, Introduction to pastoral care, Abingdon Press, Nashville, TN.

Heitink, G., 1999, Practical theology, Eerdmans, Grand Rapids, MI.

Hospice Palliative Care Association of South Africa, 2010, Palliative care standards (1st edition - August 2010 through to July 2014), viewed 14 January 2014, from http:// www.hpca.co.za/frontpage/documents.html

Kagawa, R.C., Anglemyer A. \& Montagu D., 2012, 'The scale of faith based organization participation in health service delivery in developing countries: Systematic review and meta-analysis', PLOS One 7(11), e48457. doi:10.1371/journal.pone.0048457

Koenig, H.G., King, D.E. \& Carson, V.B., 2012, Handbook of religion and health, Oxford University Press, New York.

Koenig, H.G., McCullough, M. \& Larson, D.B., 2001, Handbook of religion and health, Oxford University Press, New York.

Kourie, C., 2006, 'The "turn” to spirituality', Acta Theologica Supplementum 8, 19-38.

Lartey, E.Y., 2012, 'Pastoral theology in healthcare settings: Blessed irritant for holistic human care', in M.R. Cobb, C.M. Puchalski \& B. Rumbold (eds.), Oxford textbook on spirituality in health care, pp. 286-293, Oxford University Press, New York.

Louw, D.J., 1998, A pastoral hermeneutics of care and encounter, Lux Verbi, Wellington. Louw, D.J., 2008, Cura vitae: Illness and the healing of life, Lux Verbi, Wellington.

Manala, M.J., 2005, 'An Afro-Christian ministry to people living with HIV/Aids in South Africa', Hervormde Teologiese Studies 61(3), 897-914.

Magezi, V., 2008, 'Possibilities and opportunities: Exploring the churches' contribution to fostering national health and well-being in South Africa', Practical Theology in South Africa 23(3), 261-278.

Magezi, V., 2012, 'From periphery to the centre: Towards repositioning churches for meaningful contribution to public health care', HTS Teologiese Studies/Theological Studies 68(2), Art. \#1312, 8 pages. http://dx.doi.org/10.4102/hts.v68i2.1312

Mbigi, L., 1997, Ubuntu: The African dream in management, Sigma Press, Pretoria.

National Department of Social Development, 2011, State of South African registered non-profit organizations (2010/2011), viewed 16 December 2012, from http:// www.dsd.gov.za/npo/index.php?option=com docman\&task=doc download\&gid=73\& Itemid=39

National Planning Commission, 2013, The National Development Plan 2030: Our future make it work, viewed 15 December 2012, from http://www.gov.za/sites/www.gov.za /files/Executive \%20Summary-NDP\%202030\%20-\%200ur\%20future $\% 20-\% 20$ make\%20it\%20work.pdf

Neetling, I., 2003, 'The relevance of pastoral work in South Africa with specific reference to the Southern African Association for Pastoral Work', MTh thesis, UNISA, Adelaide. 
Osmer, R.R., 2008, Practical theology: An introduction, Eerdmans, Grand Rapids, MI. Pellegrino, E.D., 2012, 'Foreword', in M.R. Cobb, C.M. Puchalski \& B. Rumbold (eds.) Oxford textbook on spirituality in health care, p. i, Oxford University Press, New York.

Planetree, 2008, Patient-centred care improvement guide, Picker Institute, Boston, MA.

Puchalski, C.M. \& Ferrell, R.N., 2010, Making health care whole: Integrating spirituality into patient care, Templeton Press, Conshohocken, PA.

Swinton, J., 2012, 'Healthcare spirituality: A question of knowledge', in M.R. Cobb, C.M. Puchalski \& B. Rumbold (eds.), Oxford textbook on spirituality in health care, pp. 100-105, Oxford University Press, New York.
Ward, E., 2001, 'The contribution of clinical pastoral education to pastoral ministry in South Africa', Unpublished PhD thesis, Kwa-Zulu Natal University, Durban.

World Health Organisation, 1998, WHOQOL and spirituality, religiousness and personal beliefs: Report on WHO consultation, WHO, Geneva.

World Health Organisation, 2010, Key components of a well-functioning health system, viewed 14 December 2012, from http://www.who.int/healthsystems/ EN_HSSkeycomponents.pdf

World Health Organisation, 2011, Patient safety assessment manual, viewed 20 January 2014, from http://www.emro.who.int/dsaf/emropub_2011_1243.pdf?ua=1 